\title{
Rede de coautoria da Universidade Federal de Goiás: o impacto de publicações internacionais
}

\section{Co-authorship network at Federal University of Goiás: the impact of international publications}

\author{
Eduardo Alves Silva ${ }^{1}$, Dalton Lopes Martins ${ }^{1}$ \\ ${ }^{1}$ Universidade Federal de Goiás - UFG, Goiânia, GO, Brasil
}

Autor para correspondência/Mail to: Eduardo Alves Silva (easilva91@gmail.com)

Recebido/Submitted: 28 Jul. 2016; Aceito/Approved: 20 Out. 2016

Copyright (c) 2016 Silva \& Martins. Todo o conteúdo da Revista (incluindo-se instruções, política editorial e modelos) está sob uma licença Creative Commons Atribuição-NãoComercial-Compartilhalgual 3.0 Não Adaptada. Ao serem publicados por esta Revista, os artigos são de livre uso em ambientes educacionais, de pesquisa e não comerciais, com atribuição de autoria obrigatória. Mais informações em http://revistas.ufpr.br/atoz/about/submissions\#copyrightNotice.

\begin{abstract}
Resumo
Introdução: Propõe-se demonstrar a construção da coautoria dentro da Universidade Federal de Goiás (UFG) e o possível impacto da internacionalização dessa produção.

Método: foi realizada a extração de dados referentes a publicações da UFG na base de dados Web of Science (WoS) no período histórico de dezesseis anos (1999-2015), efetivando-se o tratamento do nome dos coautores das publicações de forma a construir a rede de coautoria com o uso de metodologia de análise de redes sociais (ARS).

Resultados: obteve-se a rede de coautoria de maior impacto internacional da UFG respondendo à questão sobre a existência da rede e suas características, assim como percepções sobre a internacionalização e desenvolvimento da instituição de acordo com a rede.

Conclusão: A criação da rede de coautoria demonstra a divisão de grupos e fatores que a compõem, introduzindo dessa forma contextos que vão além da coautoria, como a internacionalização e o uso das informações obtidas na gestão da pesquisa cientifica em uma instituição.

Palavras-chave: Análise de Redes Sociais; Internacionalização acadêmica; Comunicação científica
\end{abstract}

\begin{abstract}
Introduction: proposes to demonstrate the construction of co-authoring within the Federal University of Goiás (UFG) and the possible impact of this internationalization production

Method: a data extraction (concerning the temporal arch of 1999 to 2015) was performed at Web of Science (WoS) database in order to retrieve UFG publications. The items retrieved were treated - meanly the co-authors names - to build the network of co-authorship using social network analysis methodology (SNA).

Results: the co-authorship network showed the international impact of UFG which answered the question about the existence of such network and its characteristics, as well as perceptions and characteristics of internationalization and the development of the network.

Conclusions: The creation of co-authorship network demonstrates cluster divisions and related features that compose it, thus introducing contexts beyond the co-author realm, such as internationalization and the use of information obtained in the management of scientific research in an institution

Keywords: Social Network Analysis; Academic internationalization; Scientific communication.
\end{abstract}

\section{INTRODUÇÃO}

A utilização da análise de redes sociais (ARS) como método para ampliar a visão a respeito de diferentes informações e fatores que se encontram nos elementos da rede, traz possibilidades para a e análise de redes de coautoria, uma vez que esse gênero de rede se caracteriza pela colaboração entre dois ou mais autores que fazem uma publicação em conjunto. Neste tipo de rede as relações são representadas por um conjunto de nodos que estão interconectados por setas, e cuja de sua análise demonstram, univocamente, áreas e contextos de seus integrantes.

Atualmente a análise de redes de coautoria, assim como o estudo da internacionalização de produção científica servem como indicadores de desenvolvimento de um país. Como mencionado por Fiorin (2007, p. 264) "é a inserção global que indica a participação de um país na produção científica mundial”, ou no caso aqui relatado, o desenvolvimento de uma instituição. Por vezes, as redes de coautoria dizem respeito a pós-graduação ou áreas isoladas, sendo que o estudo de redes de coautoria em uma instituição permite agregar distintas áreas de conhecimento e mapear a internacionalização de sua produção como um todo.

A análise de redes sociais é definida por Marteleto (2001, p. 72), como um "sistema de nodos e elos; uma estrutura sem fronteiras, uma comunidade não geográfica; um sistema de apoio ou um sistema físico que se pareça com uma árvore ou uma rede". Este sistema traz uma abordagem expressiva que representa o todo em um meio social, e "[...]estuda as ligações relacionais (da expressão em inglês relational tie) entre atores sociais" (Matheus \& Silva, 2006, p. 1).

A construção dessas ligações relacionais, tendo como foco a coautoria de uma instituição, pode demonstrar o perfil de produção científica institucional, que se relaciona com a área do conhecimento de maior impacto na 
rede, eventualmente revelando quem são os autores que se destacam (centralidade na rede), os que possuem mais conexões, aqueles que mais se articulam com outros autores, e aqueles que mais se aproximam dos demais, criando caminhos de circulação de informação e conhecimento. Além disso, também é possível identificar comunidades ou agrupamentos de autores em torno de articulações sociais que podem revelar formas organizacionais de produzir pesquisa e publicar seus resultados podendo nos trazer novas maneiras de entender o modo como a ciência se organiza por meio da leitura de suas relações sociais.

Vale destacar que também se pode utilizar a análise de redes para avaliar o impacto real de uma área do conhecimento interna e externamente a instituição, auxiliando na visibilidade da internacionalização da produção científica. É possível, a partir da análise da rede, compreender seu desenvolvimento ao passar dos anos e perceber fatores externos que levaram determinada área do conhecimento a se destacar na rede de coautoria.

Embora a coautoria internacional possa refletir interesses, motivações e características pessoais da pesquisa de um pesquisador (Glänzel, 2001), a mesma auxilia na internacionalização de produção cientifica de um país e, nomeadamente, da área de estudo e instituição à qual se agrega o pesquisador.

\section{MOTIVAÇÃO}

A análise de redes sociais pode auxiliar em fatores estratégicos, oferecendo uma visão mais ampla de problemas ou relações que por vezes podem ser ricas ou problemáticas e não serem notadas por métodos tradicionais de análise de contexto social. Ao se aplicar a ARS à coautoria no contexto de uma instituição é possível que essa análise venha a servir de auxílio para os gestores de uma universidade que deseja produzir uma política de incentivo a qualificação de sua produção científica, bem como de estímulo a internacionalização dessa produção. Tem-se a possibilidade, igualmente, de usar a ARS como ferramenta analítica de apoio aos gestores nos processos de diagnóstico, planejamento e qualificação das redes e articulações já existentes nessa instituição. Ou seja, uma vez que se tem conhecimento das redes de coautoria internacional que se conectam a instituição, é possível produzir políticas de incentivo a essas redes, mobilizando recursos que por elas fluem para empoderar diferentes nodos, outras pessoas, e outros grupos para que estes criem caminhos de internacionalização, dado que os percursores já foram identificados, facilitando o processo. Durante a construção dessa pesquisa foi possível avaliar que isso pode beneficiar a gestão da própria instituição, alavancando ainda mais a internacionalização de produção e o amadurecimento do conhecimento em pesquisa e colaboração dos pesquisadores.

Como o estudo de análise de redes sociais aplicada a redes de coautoria apresenta peculiaridades devido ao impacto internacional representado na rede, pretende-se, nesse artigo, discutir a construção de relações de coautoria de todas as áreas do conhecimento de uma instituição, no caso a Universidade Federal de Goiás, e como essa produção relacional tem impactado na internacionalização do conhecimento.

\section{ANALISE DE REDES SOCIAIS E COAUTORIA}

O surgimento do conceito ou palavra rede está datada no seu aparecimento na língua francesa (réseau) no século XII, vindo do latim retilous, a rede designa, redes de caça ou peças de tecidos, uma malhagem têxtil que envolve o corpo (Musso, 2004, p. 18). Já em outra instância a palavra network, segundo da Silva (2014), "surge em 1908, na Conferência Internacional de Bibliografia e de Documentação, em Bruxelas, primando pelos resultados da cooperação universal disponíveis para todos, num projeto coletivo".

A conceituação e a origem das variações da palavra rede são notáveis, sendo que suas primeiras menções foram fatores que vieram a determinar a atual conceituação que se tem a respeito de redes e análise de redes sociais. Uma colocação que engloba de forma tanto o conceito de redes quanto o de ARS é a de Musso (2004), para o qual "a rede é um veículo que nos transmuda em "passantes", sempre mergulhados nos fluxos (de informações, de imagens, de sons, de dados...) ". Em termos gerais a possibilidade de se enxergar o todo torna a ARS um ambiente de compreensão social, informacional e causal, que por sua vez traz para o estudo de coautoria possibilidades valiosas de análise.

Os estudos sobre análise de redes sociais com temas voltados para colaboração e coautoria tem aumentado, como mencionado por de Fátima S. Maia e Caregnato (2008, p. 20)):

Associado aos trabalhos sobre co-autoria, atualmente também se observa um fortalecimento do método de análise de redes sociais nos estudos sobre colaboração científica, o que possibilita uma visão abrangente das interações entre as partes, diferentemente das análises que enfocam características individuais.

Assim, é possível se constatar o interesse relacionado à colaboração cientifica e um dos seus muitos aspectos a coautoria, embora o estudo da coautoria não demonstre todas as tramas da colaboração cientifica, tal como explicitado por de Souza Vanz e Stumpf (2010, p. 45), no trecho a seguir: 
A colaboração científica aparece muitas vezes na literatura relacionada à co-autoria. Frequentemente, os dois termos são considerados sinônimos pelos pesquisadores, mas convém afirmar que a co-autoria é apenas uma faceta da colaboração científica, pois ela não mede a colaboração na sua totalidade e complexidade.

Ao ser associada à análise de redes sociais, uma rede de coautoria desperta interesse pelas possibilidades de compreensão e visualização de forma ampla de interações, harmonizando dessa forma a compreensão de questões relacionadas ao amadurecimento de uma instituição no desenvolvimento científico (e nomeadamente na pesquisa) dado o envolvimento e impacto de colaborações e estudos de seus pesquisadores. Uma vez que a coautoria ocorre por vezes entre áreas e instituições distintas, há, potencialmente, um maior impacto em publicações.

A escolha do estudo da rede de coautoria, em suma, se dá por facilitadores, tais como a possibilidade de coleta de dados na instituição, e as oportunidades da ARS como mencionadas por de Oliveira e Silva, Matheus, Parreiras, e Parreiras (2006, p. 77) no trecho a seguir:

O uso da ARS vem crescendo significativamente nos últimos 20 anos. Tal crescimento vem ocorrendo em função do aumento da quantidade de dados disponíveis para análise, do desenvolvimento nas áreas de informática e processamento de dados - com o consequente aumento do poder computacional à disposição dos pesquisadores -, e da ampliação dos assuntos de interesse e das áreas de conhecimento que utilizam a ARS.

Além de indicadores de rede que disponibilizam a análises de fatores que circulam a rede, é possível utilizar uma forma de visualização de um ambiente único.

Para o estudo e análise da rede podem ser utilizados como métricas os indicadores de rede destacados por Wasserman e Faust (1994), além de Cherven (2015), em um livro que descreve de forma detalhada o uso da ferramenta de análise de redes complexas Gephi, que é a ferramenta utilizada no desenvolvimento dessa pesquisa. A Quadro 1 lista os indicadores utilizados e seus significados.

\begin{tabular}{|l|l|}
\hline Indicadores & Significado \\
\hline Nós & Representação de pessoas que fazem parte da rede. \\
\hline Relações (links) & Número de relações existentes entre as pessoas. \\
\hline Centralidade de Grau & Ator da rede com maior atividade ou relações, em relação aos demais. \\
\hline Centralidade de Proximidade & $\begin{array}{l}\text { Um segundo ponto de vista de centralidade baseado em proximidade ou distância. A medida incide } \\
\text { sobre o quão perto um ator é para todos os outros intervenientes no conjunto de atores. }\end{array}$ \\
\hline Centralidade de Intermediação & $\begin{array}{l}\text { Demonstram nodos da rede que gera uma interação entre dois atores não adjacentes, servindo como } \\
\text { ponte para se chegar a um determinado ator ou comunidade. }\end{array}$ \\
\hline Modularidade & Abordagem estatística que mede o agrupamento numa rede, definindo comunidades na rede. \\
\hline Coeficiente de Clusterização & $\begin{array}{l}\text { O coeficiente de agrupamento possibilita medir em que nível os nós são agrupados em conjunto, } \\
\text { demonstrando como os nós estão inseridos em sua vizinhança. }\end{array}$ \\
\hline Componentes Conectados & $\begin{array}{l}\text { Número de componentes distintos na rede. Normalmente componentes que estão separados ou } \\
\text { isolados da rede. }\end{array}$ \\
\hline
\end{tabular}

Quadro 1. Indicadores de análise de redes sociais.

Fonte: Wasserman e Faust (1994); Cherven (2015).

\section{METODOLOGIA}

O processo que envolve o desenvolvimento da rede de coautoria de maior impacto internacional da Universidade Federal de Goiás dividiu-se em três etapas distintas, sendo elas a coleta e tratamento dos dados, passando pela sua estruturação e a análise dos resultados.

De forma a se estruturar toda a pesquisa, foram utilizadas as seguintes ferramentas/plataformas: a base de dados da Web of Science (WoS); o kit Office como ferramenta de tratamento de dados; a construção de um script na linguagem web PHP (que auxiliou no tratamento dos dados necessários para se gerar a rede de coautoria); e, o software de análise de redes complexas Gephi, que tem como papel auxiliar na visualização e análise da rede de coautoria.

\section{Coleta e Tratamento de Dados}

A utilização da Web of Science como base de dados para a coleta de informação se deu pela vasta gama de publicações armazenadas, pois “...inclui mais de 10.000 periódicos e é composto por sete bases de dados diferentes de citações, incluindo diferentes informações coletadas de revistas, conferências, relatórios, livros e séries de livros” (Chadegani et al., 2013, p. 19, tradução nossa), assim como sua facilidade de busca em relação aos dados que se mostraram necessários durante o desenvolvimento da pesquisa.

Para obtenção dos dados necessários, coletaram-se todas as publicações da Universidade Federal de Goiás dentro da WOS com o uso de algoritmo de busca demonstrado no Quadro 2, efetuando-se a coleta de todas publicações da UFG - entre o período 1999 e 2015 - resultando em 3.007 publicações (em sua maioria artigos). 
Quadro 2. Algoritmo de busca para obtenção de publicações da Universidade Federal de Goiás.

Nota: $A D=$ Nome da instituição a qual deseja que as publicações sejam pesquisadas.

Fonte: Thomsom Reuters - Web Of Science.

Uma vez que a WoS possibilita que a exportação dos resultados da da busca em planilha de apenas 500 registros por vez, foram necessárias várias exportações até se conseguir todos os registros. Ao final da exportação os dados foram reunidos em uma única planilha.

O tratamento dos dados incluiu a separação dos coautores das publicações, uma vez que as planilhas exportadas da WoS trazem todos coautores de uma publicação em uma mesma célula, separados apenas por ponto e vírgula (Quadro 3).

\begin{tabular}{|ll|}
\hline Publicações & Coautores \\
\hline Publicação 1 & Coautor 1; Coautor 2; Coautor 3 \\
\hline
\end{tabular}

Quadro 3. Representação de dados da planilha exportada a partir da WoS.

Fonte: os autores.

Ao se detalhar da divisão por ponto e vírgula pretende-se justificar a etapa de separação dos coautores, a qual influencia na criação de relações para o desenvolvimento da rede de coautoria. Os coautores foram, portanto, extraídos dos dados gerais e separados entre colunas em um arquivo de formato CSV (dados separados por vírgulas).

Ao se obter o arquivo com todos os nomes devidamente separados por colunas e não mais em uma única coluna com ponto e vírgula, fez-se necessária a criação de relações entre esses coautores (Quadro 4).

\begin{tabular}{|ll|}
\hline Publicações & Relações \\
\hline Publicação 1 & Coautor 1 - Coautor 2 \\
& Coautor 1 - Coautor 3 \\
& Coautor 2 - Coautor 3 \\
\hline
\end{tabular}

Quadro 4. Representação de dados da planilha exportada a partir da WoS.

Fonte: os autores.

O Quadro 4 representa as relações entre os coautores de uma publicação. Essa representação é crítica ao presente estudo devido aos fatores de análise de redes sociais que necessitam da construção de ligações para gerar a rede de coautoria. Para que a construção de laços entre coautores se desse da forma apresentada na tabela 3, de acordo com os dados já tratados, criou-se um pequeno programa computacional em PHP (um script) (Apêndice A), que fez a leitura do arquivo .csv (onde os nomes se encontravam), separando-os em colunas. É importante ressaltar que um dos resultados obtidos a partir do script é a possibilidade de coleta dos dados necessários para a representação da lista de arestas ou ligações exigidas no Gephi, e é similar ao demonstrado no Quadro 4.

Um fator que deve ser levado em consideração na criação da rede é o que indica que, em termos de ligações, o número é absoluto, pois a variação de nomes não interfere nas mesmas. No entanto, o número de coautores pode vir a sofrer alguma alteração decorrente da repetição de nomes (e não em termos de ligações) (Quadro 5).

\begin{tabular}{|ll|}
\hline Publicações & Nomes \\
\hline \multirow{2}{*}{ Publicação 1 } & Eduardo, A. S. \\
& Silva, Eduardo A. \\
& A, Eduardo Silva \\
\hline
\end{tabular}

Quadro 5. Representação da repetição/variação de nomes de um coautor.

Fonte: os autores.

Essa variabilidade de representações de nomes pode ser um fator prejudicial para a análise da rede, uma vez que irá produzir conexões diferentes do mesmo coautor, não demonstrando de forma totalmente coerente sua importância na rede. Tal situação gera uma quantidade significativa de nomes a serem desambiguados. Efetuar tais correções seria um esforço manual intenso e, dado o tempo disponível para a pesquisa, impeditivo. Entre as diferentes formas de se resolver tal problema, a sugerida por Newman (2001) explora o seguinte processo:

Em primeiro, nós identificamos cada autor por seu sobrenome e sua primeira inicial apenas. Este método é claramente propenso a confundir duas pessoas para uma, mas raramente irá falhar para identificar dois nomes que genuinamente se referem a mesma pessoa. [...], nós identificamos autores pelo sobrenome e suas iniciais. Este método pode distinguir com mais fiabilidade os autores um dos outros, mas também identifica uma pessoa como diferente se suas iniciais forem diferentes em diferentes trabalhos. (Newman, 2001, p. 3, tradução nossa)

Em termos de correção dos nomes, o método utilizado segue o mesmo princípio: caso um nome tenha suas iniciais similares a um nome já identificado - e não se obtenha dentro da base qualquer outro nome com essas 
iniciais - se dá como definido que se trata do mesmo nome, fazendo assim sua alteração. Em casos onde existe a ocorrência de iniciais e dois ou mais sobrenomes, a busca por similaridade de nomes se dá por exclusão de sobrenomes.

No entanto, por conta da quantidade de nomes recuperados na base propôs-se, para este estudo, um outro método. Desambiguaram-se apenas os nodos que possuíam um número mínimo de conexões em rede. Ou seja, o critério adotado foi de relevância pelo impacto que esse nodo produz na rede. Aqueles nodos que tiveram um número significativo de conexões (a ser estabelecida quando da análise dos dados), foram identificados em maior detalhe, inclusive para busca de atributos qualitativos (unidade de origem, área de atuação etc.). Dessa maneira, assumiu-se como pressuposto que esse formato reduziria o tempo de trabalho e entregaria um resultado que permita interpretar as estratégias de relação entre os nodos sem perda significativa de nosso potencial de entendimento da rede.

Para se chegar aos nomes que deveriam ser tratados de acordo com o critério de relevância, propôs-se uma análise pelo corte de grau. Como todos os coautores têm um número de aparições na base de dados, esse número na rede se converte em grau de centralidade, demonstrando os coautores com mais ligações e, portanto, que podem ser considerados mais relevantes na rede. Dessa forma, a partir da contagem de nomes obteve-se o grau (número de vezes que aparecem na base) para cada autor. Verificou-se, então, quantas vezes o grau de cada coautor se repete nos dados. Após essa verificação, alguns graus podem aparecer mais de uma vez (como é o caso de coautores que se repetem apenas uma vez nos dados) o que representa a quantidade de vezes que esse nome apareceu na rede. Assim, passou-se ao corte de grau, a partir de intervalos de aproximadamente nove ou dez nomes que, somando-se o grau (consoante a sua repetição) revelou uma maior ocorrência.

Torna-se importante atentar a esta etapa, pois, como mencionado anteriormente, ao se procurar os nomes com maior relevância, ou seja, que podem aparecer mais vezes nos dados, isto indica que o seu valor de grau é muito maior que o dos outros. Sendo assim, um coautor que aparece mais na rede e que exige o tratamento de seu nome, terá maior impacto de forma geral.

Um outro tratamento exigido foi o da classificação dos periódicos que publicam os artigos coletados. Efetivou-se uma contagem dos periódicos sem que houvesse duplicação dos títulos de tais periódicos. Após a contagem fezse a busca manual e a identificação de proveniência, sendo que, posteriormente, realizou-se a classificação entre periódicos nacionais e internacionais. Esse processo mostrou-se trabalhoso, uma vez que muitos periódicos não apresentavam identificação de país de procedência, agregavam diferentes idiomas ou não possuíam site com mais informações. Dessa forma, para contornar essas dificuldades, periódicos brasileiros com foco internacional foram classificados como internacionais e alguns periódicos foram identificados como internacionais não identificados.

\section{Estruturação de dados e criação da rede}

Após o tratamento dos nomes dos autores, passou-se para a estruturação dos dados para a criação a rede de coautoria. Como já mencionado, foram necessários dois arquivos predispostos de maneiras diferentes, uma planilha com os nodos (nodes) e outra com as arestas (edges).

Para estruturar o primeiro arquivo, a planilha de nodos, foram utilizados os nomes sem repetição, estando ordenados ou não. A primeira coluna elencava tais nomes e outra coluna, nomeada de ID, se atribuiu uma identificação numérica para esses nomes (Quadro 6).

\begin{tabular}{|ll|}
\hline Label & ID \\
\hline Coautor 1 & 1 \\
Coautor 2 & 2 \\
Coautor 3 & 3 \\
\hline
\end{tabular}

Quadro 6. Identificação numérica dos nomes dos coautores - exemplo.

Fonte: os autores.

O resultado no Quadro 6 é uma classificação numérica dos nomes cujos ids são únicos. Os números associados aos nomes irão estruturar as relações no arquivo de arestas, como é mostrado no Quadro 7.

\begin{tabular}{|lll|}
\hline Source & Target & Weight \\
\hline 1 & 2 & 1 \\
1 & 3 & 1 \\
2 & 3 & 1 \\
\hline
\end{tabular}

Quadro 7. Planilha de arestas (edges).

Fonte: os autores.

A Planilha de arestas traz algumas diferenças se comparada a de nodos em decorrência das relações em si que estão classificadas não pelos nomes, mas sim pelo ID de cada nome - além de trazer alguns classificadores 
diferentes. A estrutura ocorre a partir do link entre os coautores (source) e para onde esse link está direcionado (target), gerando, assim, as arestas ou ligações entre autores. Adiciona-se a esta estrutura o indicador que atribui o valor do peso das arestas (weight), cujo cálculo é feito pelo próprio Gephi, demonstrando a importância ou peso de cada conexão.

Com a estruturação dos dados de base foi possível criar a rede de coautoria, importando estes arquivos para o Gephi.

\section{RESULTADOS}

\section{Tratamento de nomes}

A obtenção de resultados deu-se a partir do tratamento inicial dos dados explicitado em tópicos anteriores. Um dos primeiros resultados diz respeito ao número de coautores e ligações obtidos (Tabela 1).

\begin{tabular}{cc}
\hline Relações & Número de Coautores \\
\hline 48.857 & 8.482 \\
\hline
\end{tabular}

Tabela 1. Relações/ligações obtidas e o número de Coautores.

Fonte: os autores.

Em seguida obteve-se novos resultados a partir da classificação de nomes dos coautores com base em seus graus, dispostos do maior para o menor grau. Os intervalos, por sua vez, foram classificados no sentido contrário, ou seja, do menor para o maior grau. A Tabela 2 representa os intervalos e a soma do grau entre esses intervalos.

\begin{tabular}{lc}
\hline Intervalo & Soma de ocorrências de grau por intervalo \\
\hline $0-10$ & 6177 \\
$11-20$ & 1782 \\
$21-30$ & 438 \\
$31-40$ & 163 \\
$41-50$ & 84 \\
$51-60$ & 42 \\
$61-70$ & 31 \\
$71-80$ & 28 \\
$81-90$ & 20 \\
$91-100$ & 18 \\
$101-110$ & 12 \\
$111-120$ & 11 \\
$121-125$ & 5 \\
\hline
\end{tabular}

Tabela 2. Classificação de ocorrência por intervalo.

Fonte: os autores.

Percebe-se que o intervalo inicial 0-10 tem uma soma maior de ocorrências, sendo que são nomes da base que ocorreram várias vezes, mas têm um grau menor, e seu tratamento seria dispendioso em termos de tempo e esforço, não resultando em impacto significativo na visualização posterior dos dados. O tratamento se deu a partir do corte de grau de 41-50, onde se encontra o declínio de ocorrência até 121-125, ou seja: todo o intervalo anterior a 41-50 tem uma repetição significativa de grau - onde, por exemplo, cerca de 6177 autores aparecem apenas uma vez na rede. Com isso houve uma redução de 329 nomes dos 8.811 iniciais, em um total final de 8.482. Embora, em termos gerais, esta redução possa parecer inócua, o real impacto está nas relações entre os nomes da rede.

De forma a exemplificar este impacto, a Figura 1 permite visualizar os vinte primeiros nomes mais expressivos derivados dos dados, omitidas as repetições/duplicações. A representatividade dos nomes e o número de aparições de cada um tem impacto direto nos indicadores de rede.

\section{Internacionalização da produção cientifica}

Quanto à internacionalização dos periódicos, verificou-se que a publicação em periódicos nacionais representa 60\% do total de títulos, enquanto outros 33\% são publicações em periódicos internacionais.

Como mencionado por Katz (2000) a partir do seu estudo sobre indicadores e avaliação de pesquisa, o tamanho de uma instituição ou nação, pode influenciar em relação ao nível de colaboração e coautoria internacional.

Demonstrou-se que o reconhecimento e impacto aumentaram em uma relação de lei de potência com o tamanho de uma instituição, comunidade ou nação. Colaboração expõe uma relação de lei de potência com o tamanho de uma instituição. (Katz, 2000, p. 29, tradução nossa) 


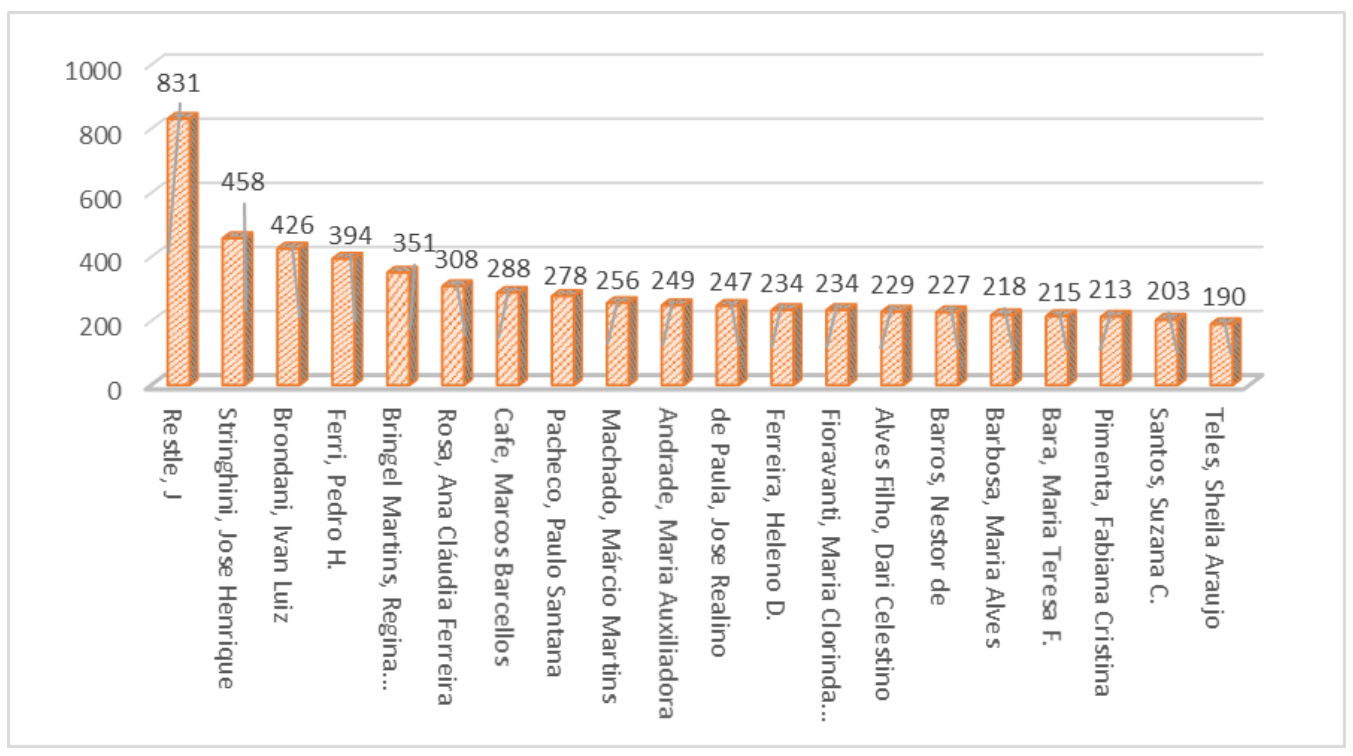

Figura 1. Frequência - nomes dos coautores - Universidade Federal de Goiás (1999-2015).

Fonte: os autores.

Dessa forma ao se relacionar esta afirmativa com os dados obtidos, algumas considerações podem ser levantadas, nomeadamente:

a) uma vez que o tamanho da instituição exerce impacto sobre o nível de colaboração/coautoria internacional, pode-se dizer que a UFG necessita avanças na internacionalização.

b) embora a afirmação anterior possa ser verdadeira, um outro fator pode ser considerado. Como nação, a extensão do território brasileiro pode levar a colaboração científica em território nacional, com instituições com melhor posicionamento nacional e mundial, como é o caso da Universidade de São Paulo.

c) outra possibilidade seria a da dificuldade de pesquisadores em publicarem com colaboração ou coautoria internacional devido a fatores tais como: interesse pessoal ; possível falta de estrutura (que pode influenciar na qualidade e coerência do trabalho, o que pode prejudicar a colaboração científica no escopo nacional e internacional).

De forma a elucidar os resultados apresentados, a Tabela 3 apresenta a variação geral em relação a internacionalização, ressaltando-se uma frequência significativa de publicações em títulos publicados no território nacional, comparativamente à soma dos demais países.

\begin{tabular}{lc}
\hline Países & Soma de ocorrências de grau por intervalo \\
\hline Brasil & 237 \\
Brasil (internacional) & 44 \\
Holanda & 14 \\
USA & 11 \\
Chile & 10 \\
Internacional (n/identificado) & 10 \\
Inglaterra & 7 \\
Colômbia & 6 \\
Portugal & 5 \\
Argentina & 3 \\
Espanha & 3 \\
Alemanha & 1 \\
Canadá & 1 \\
Costa Rica & 1 \\
México & 1 \\
Peru & 1 \\
Uruguai & 1 \\
\hline
\end{tabular}

Tabela 3. Internacionalização na Universidade Federal de Goiás - quantidade publicações por títulos periódicos - ordenados por País (19992015).

Fonte: os autores.

Ainda que a Holanda apareça como um dos principais países que publicam os periódicos nos quais os pesquisadores da UFG divulgam suas contribuições, isso pode ser derivado da área de publicação ou mesmo a centralização desse repositório entre aqueles em que o pesquisador pode optar por publicar. Tais dados parecem indicar que a UFG - ao se levar em conta que o "peso" da produção científica de cada país, "é aquela publicada em periódicos reconhecidos mundialmente, lidos, citados” (Fiorin, 2007, p. 267) - necessita aumentar os esforços em direção 
a publicações internacionais.

Entretanto, não existem ainda estudos voltados para fatores de internacionalização dentro de uma instituição especifica. Porém, em números absolutos a UFG apresenta avanços em busca da visibilidade a nível internacional, orientando-se para os processos de cooperação e internacionalização como forças motoras do desenvolvimento científico e tecnológico (Balbachevsky, 1998, p. 200).

\section{Análise descritiva dos dados}

A partir da análise feita sobre os dados obtidos, foram geradas algumas informações adicionais, tais como a média de coautoria anual da instituição, entre outros fatores. A Figura 2 representa a quantidade total de artigos publicados por ano, de acordo com os dados coletados.

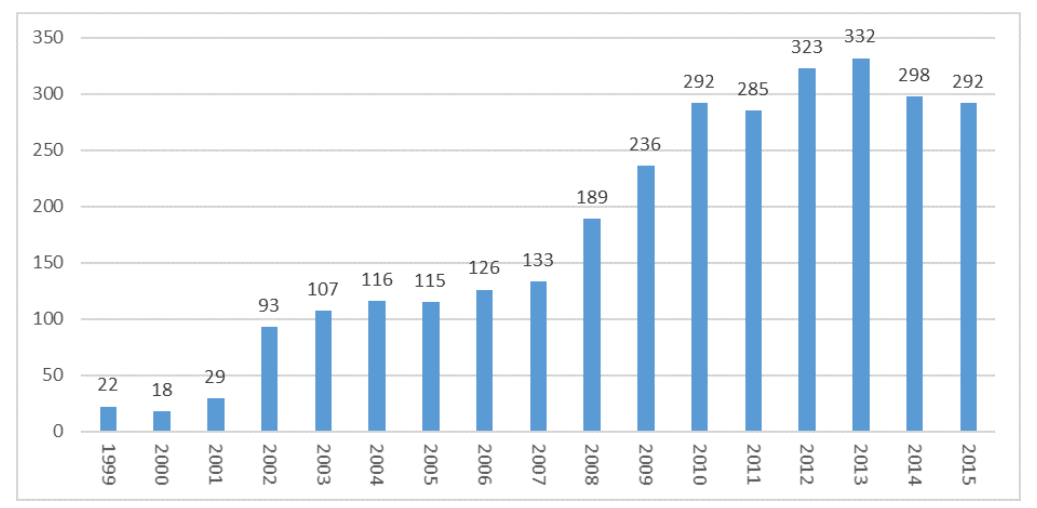

Figura 2. Quantidade de artigos publicados por ano - Universidade Federal de Goiás (1999-2015).

Fonte: os autores.

É possível perceber que, a partir dos anos de 2002, 2003, inicia-se um crescimento em relação a quantidade de artigos publicados por ano. Tal crescimento vai até o ano de 2013 havendo uma queda subsequente nos dois anos seguintes. No período entre 2003 e 2013, o crescimento pode estar relacionado ao Programa de Reestruturação e Expansão das Universidades Federais (Reuni) do Governo Federal - que esteve em atividade entre os anos de 2003 e 2012. Tal Programa se propôs a alavancar o crescimento e desenvolvimento das Universidades Federais em pontos estratégicos relacionados expansão física, acadêmica e pedagógica. Porém, tal relação necessitaria um estudo mais aprofundado. A Figura 3 representa a média de coautoria anual, da instituição durante o período estudado.

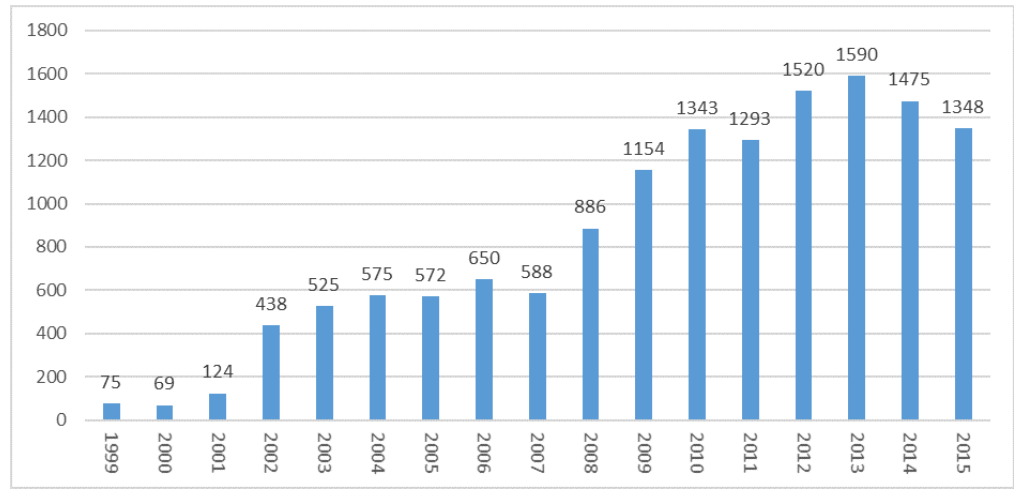

Figura 3. Número de coautores por ano - Universidade Federal de Goiás (1999-2015).

Fonte: os autores.

A similaridade da Figura 3 com a Figura 02 permite verificar que o crescimento no número de artigos normalmente está diretamente relacionado a mais autores e por consequente, mais coautores. No ano de 2013, por exemplo, há um total de 332 artigos publicados com 1.590 coautores. A Figura 4, por sua vez, representa a média de coautoria por artigo e por ano.

É possível perceber que a média de coautoria segue padrões bem definidos durante cada período, tendo um leve aumento entre 2000 e 2002, se mantendo entre 2002 e 2010, onde volta a baixar, ainda que não de forma abrupta. Embora essa média seja constante, não se pode dizer que ela realmente representa o que ocorre nos dados, pois há publicações com dois coautores (mínimo encontrado) e, publicações com o máximo de dezessete coautores. Assim, a média aqui apresentada tem o objetivo de ilustrar uma discrepância em relação aos dados.

A relação da quantidade de periódicos, na WoS, onde autores da UFG publicam a cada ano demonstra-se variada ainda que em evolução constante (Figura 5). Constata-se que alguns periódicos são comuns aos coautores da 


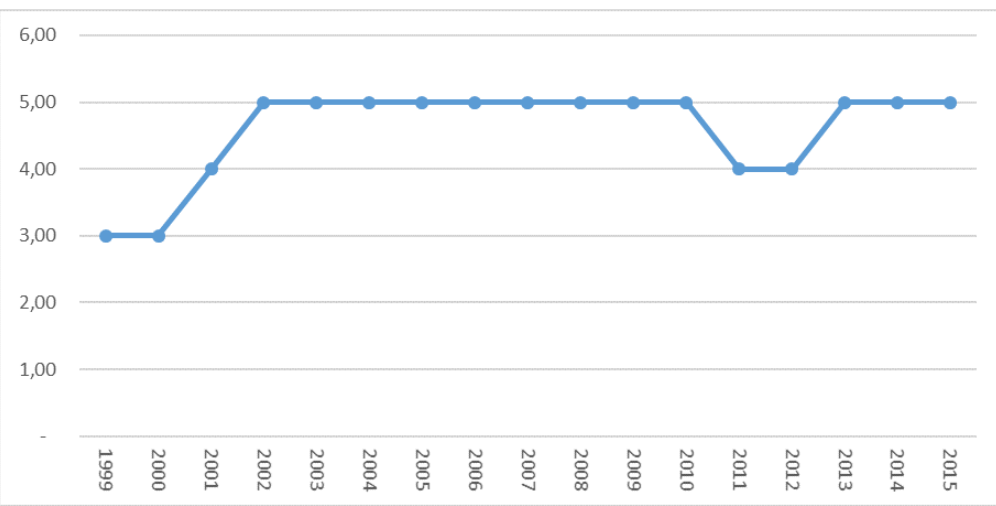

Figura 4. Média de coautoria por artigo - Universidade Federal de Goiás (1999-2015).

Fonte: os autores.

UFG, sendo que a média de publicação por periódico seja em torno de 2,12 publicações nos 382 periódicos da WoS nos quais os pesquisadores da UFG publicaram nestes 16 anos.

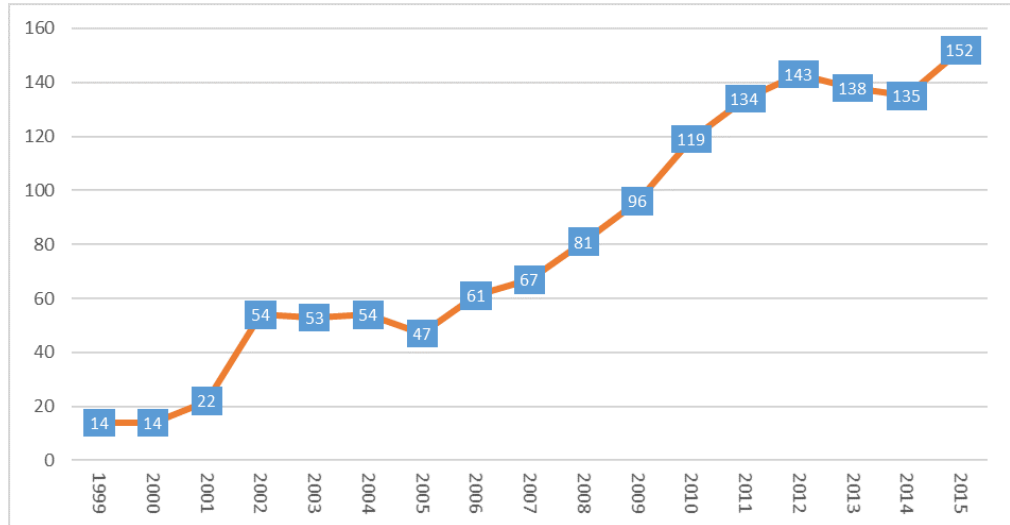

Figura 5. Média de Periódicos por Ano - Universidade Federal de Goiás (1999-2015).

Fonte: os autores.

Dentre os periódicos listados, alguns que aparecem com mais frequência na base de dados estão provavelmente ligados à área de atuação dos pesquisadores mais expressivos da rede (Tabela 4).

\begin{tabular}{lc}
\hline Periódicos & Quantidade de aparições na base \\
\hline Revista Brasileira de Zootecnia & 120 \\
Ciência Rural & 90 \\
Revista da Sociedade Brasileira de Medicina Tropical & 83 \\
Memorias do Instituto Oswaldo Cruz & 71 \\
Radiologia Brasileira & 63 \\
Arquivo Brasileiro de Medicina Veterinária e Zootecnia & 62 \\
Journal Of The Brazilian Chemical Society & 55 \\
Pesquisa Agropecuária Brasileira & 55 \\
Arquivos Brasileiros de Oftalmologia & 44 \\
Ciência e Agro Tecnologia & 43 \\
\hline
\end{tabular}

Tabela 4. Periódicos mais expressivos na base de dados WoS - - Universidade Federal de Goiás (1999-2015).

Fonte: os autores.

Os periódicos mais expressivos estão voltados em sua maioria para as áreas das Ciências Agrarias, isso é um forte reflexo da localização geográfica a instituição, uma região que tem fortes características agropecuaristas.

\section{Análise da rede de coautoria da Universidade Federal de Goiás}

A Figura 6a permite visualizar - por cores e alguns clusters ou comunidades circuladas - a rede de coautoria da UFG. As comunidades circuladas são comunidades com ligações mais fortes entre si gerando assim atores da rede que estão mais próximos. Em alguns casos é possível reparar por conta das cores que existem outras comunidades que não se mostram tão densas, mas sim bastante dispersas na rede, isso pode ocorrer por conta do quão forte são suas ligações.

Embora a modularidade aplicada a uma rede de tal densidade possa demonstrar algumas divergências se comparada a atributos que dividem a mesma - tais como as áreas de atuação ou ano de ingresso nos dados 


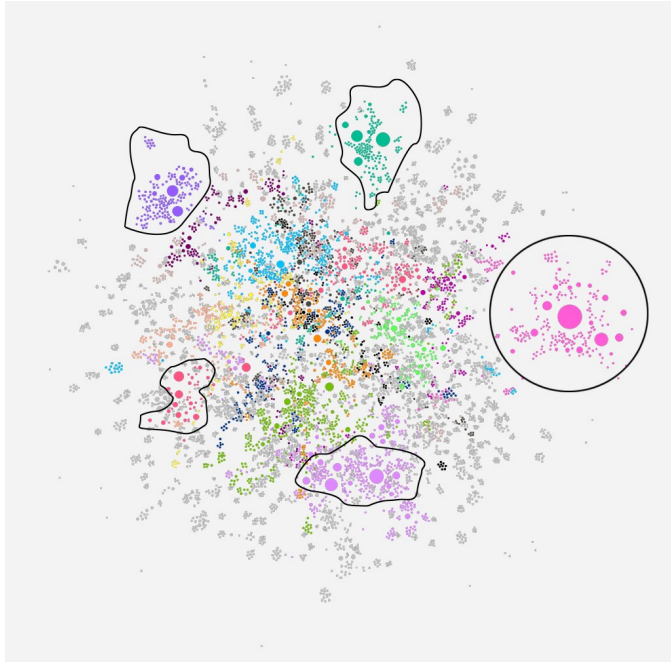

(a)

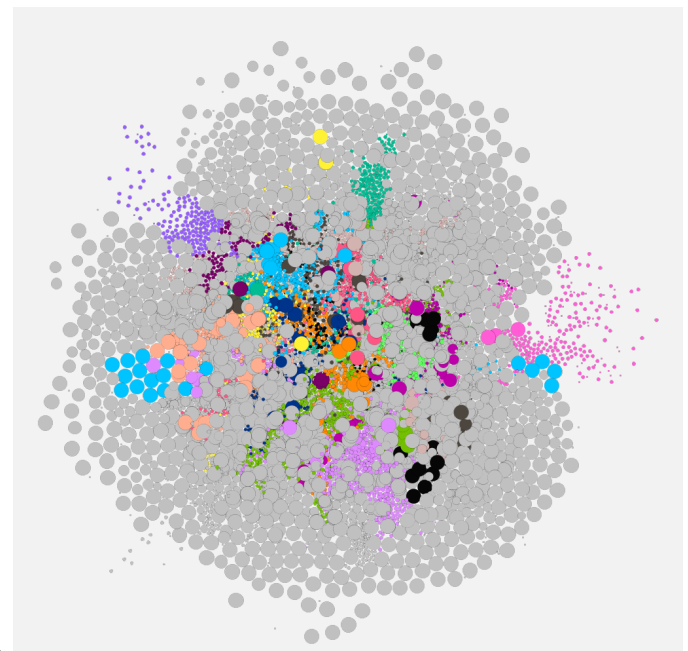

(c)

Figura 6. (a) Rede de Coautoria - Universidade Federal de Goiás - (1999-2015). (b) Rede de coautoria - centralidade de proximidade (Universidade Federal de Goiás - 1999-2015). (c) Rede de Coautoria - centralidade de intermediação (Universidade Federal de Goiás - 1999 2015).

Fonte: os autores.

- o número de comunidades identificadas é expressivo (total de 548 comunidades). Além disso, um segundo indicador diz respeito a centralidade de grau. Pode-se perceber que a comunidade rosa mais clara, a direita da figura, tem o nodo com maior centralidade de grau de toda a rede.

A Figura $6 \mathrm{~b}$ demonstra que todos os nodos maiores são aqueles que estão próximos de todos os outros dentro da rede. O que torna essa visualização interessante é o fato do nodo que anteriormente tinha a maior representação enquanto a centralidade de grau, nessa visualização não demonstra tanta relevância. Ou seja, caso um ator externo queira adentrar mais a rede, talvez o nodo com maior centralidade de grau não seja a melhor opção, uma vez que - embora o mesmo tenha muitas ligações e grande importância na rede - quando se diz respeito a se conectar ou estar próximo de outros nodos da rede, ele não se demonstra tão relevante.

O último parâmetro analisado é o indicador de centralidade de intermediação, que demonstra os nodos que servem como ponte dentro da rede. Ou seja, para se chegar a uma determinada comunidade ou nodo dentro da rede, esse nodo em específico será o intermediário. Como demonstrado na Figura 6c (seta vermelha), o nodo/ator com maior grau de centralidade de intermediação dentro da rede interconecta diferentes outros atores de comunidades distintas. Em alguns casos ele se conecta a atores importantes de determinadas comunidades. Sendo assim, este é o ator da rede a ser procurado caso se queira conhecer novas áreas da rede.

Um dos indicadores que deve ser considerado durante a análise de redes é o de componentes conectados. Este indicador demonstra a quantidade de componentes da rede que estão fortemente conectados, assim como os que têm ligações mais fracas com o todo da rede. Neste último caso as ligações fracas são aquela que, normalmente, provêm de atores que estão mais afastados da rede. No caso da UFG foram encontrados 514 nodos com ligações fracas. Em termos gerais não é um bom fator ter nodos afastados; no entanto, muitos desses nodos estão conectados a redes externas à estudada, podendo assim trazer uma maior expansão a rede atual, ou servir de intermediação para um maior nível de colaboração entre redes distintas, tornando-se assim um fator importante a ser observado na análise de redes. 


\section{CONCLUSÃO}

O estudo de análise de redes sociais traz inúmeras informações a respeito de uma determinada comunidade ou grupo que interage entre si, neste estudo foi demonstrado o potencial desse tipo de análise aplicado a algo bastante comum em termos acadêmicos, a coautoria.

A visão macro de toda a rede e a possibilidade e aplicabilidade do uso de atributos que tornam a rede única, fazem com que o estudo e obtenção de possíveis fatores que expliquem os "porquês" das relações, sejam um ativo informacional bastante relevante para uma instituição ou mesmo governo (caso se pretenda a discussão em nível nacional). Uma visão macro e a apresentação de indicadores tende a facilitar a busca de informações adicionais, tais como o porquê de determinado ator ser o nodo da rede com mais ligações, e o que faz com que ele seja o mais importante? O investimento do governo ou da própria instituição está atrelado a esse fato? A formação, networking ou mesmo o posicionamento geográfico da instituição, influenciam para que este ator seja o mais relevante em termos de conexão? Os fatores são diversos e a visualização da rede em si não oferece respostas completas ainda que auxilie na construção de pressupostos e hipóteses a serem discutidas posteriormente.

Contudo, os fatores de internacionalização da Universidade Federal de Goiás merecem estudos mais aprofundados quanto ao impacto das políticas públicas nacionais e da própria instituição neste sentido.

Em um contexto geral, a análise de redes sociais, traz insights como demonstrados neste estudo, possibilitando recortes mais exploratórias e imersivas que por sua vez irão agregar informações em diferentes níveis para aqueles que fazem uso desse método. Os gestores de uma instituição, com o uso desses métodos de análise, podem ter um fator a mais de tomada de decisão voltada aos investimentos em diferentes segmentos/áreas do conhecimento com impactos mensuráveis no desenvolvimento cientifico da instituição. 


\section{REFERÊNCIAS}

Balbachevsky, E. (1998, Jun.). Uma janela de oportunidades para a sociologia da ciência. Revista Brasileira de Ciências Sociais, 13(37), 197-201. doi: 10.1590/S010269091998000200012

Chadegani, A. A., Salehi, H., Yunus, M. M., Farhadi, H., Fooladi, M., Farhadi, M., \& Ebrahim, N. A. (2013). A Comparison between Two Main Academic Literature Collections: Web of Science and Scopus Databases. Asian Social Science, 9(5), 18-26. doi: 10.5539/ass.v9n5p18

Cherven, K. (2015). Mastering Gephi network visualization. Birmingham: Packt Publishing.

da Silva, A. K. A. (2014). A dinâmica das redes sociais e as redes de coautoria. Perspectivas em Gestão \& Conhecimento, 4(Número Especial), 27-47. Recuperado de http://periodicos .ufpb.br/ojs2/index.php/pgc/article/view/21275

de Fátima S. Maia, M., \& Caregnato, S. E. (2008, Maio/Ago.). Co-autoria como indicador de redes de colaboração científica. Perspectivas em Ciência da Informação, 13(2), 18-31. doi: 10.1590/S1413-99362008000200003

de Oliveira e Silva, A. B., Matheus, R. F., Parreiras, F. S., \& Parreiras, T. A. S. (2006, Jan./Abr.). Análise de redes sociais como metodologia de apoio para a discussão da interdisciplinaridade na ciência da informação. Ciência da Informação, 35(1), 72-93. doi: 10.1590/S0100-19652006000100009

de Souza Vanz, S. A., \& Stumpf, I. R. C. (2010, Maio/Ago.). Colaboração científica: revisão teórico-conceitual. Perspectivas em Ciência da Informação, 15(2), 42-55. doi: 10.1590/S141399362010000200004

Fiorin, J. L. (2007). Internacionalização da produção científica: a publicação de trabalhos de ciências humanas e sociais em periódicos internacionais. Revita Brasileira de Pós-Graduação, 4(8), 263-281. doi: 10.21713/23582332.2007.v4.133

Glänzel, W. (2001, April). National characteristics in international scientific co-authorship relations. Scientometrics, 51(1), 69-115. doi: 10.1023/A:1010512628145

Katz, J. S. (2000). Scale-independent indicators and research evaluation. Science and Public Policy, 27(1), 23-36. doi: 10.3152/147154300781782156

Marteleto, R. M. (2001, Jan./Abr.). Análise de redes sociais: aplicação nos estudos de transferência da informação. Ciência da Informação, 30(1), 71-81. doi: 10.1590/S010019652001000100009

Matheus, R. F., \& Silva, A. B. O. (2006). Análise de redes sociais como método para a Ciência da Informação. DataGramaZero, 7(2), 1-17.

Musso, P. (2004). A filosofia da rede. In A. Parente (Ed.), Tramas da rede: Novas dimensões filosóficas, estéticas e políticas da cognição (p. 17-38). Porto Alegre: Sulinas.

Newman, M. E. J. (2001). Scientific collaboration networks: Network construction and fundamental results. Physical Review E, 64(1). doi: 10.1103/PhysRevE.64.016131

Wasserman, S., \& Faust, K. (1994). Social network analysis: Methods and applications (structural analysis in the social sciences). Cambridge: Cambridge University.

Como citar este artigo (APA):

Silva, E. A. \& Martins, D. L. (2016). Rede de coautoria da Universidade Federal de Goiás: o impacto de publicações internacionais. AtoZ: novas práticas em informação e conhecimento, 5(2), 91 - 103. Recuperado de: http://dx.doi.org/10.5380/atoz.v5i2.47854 


\section{APÊNDICE A - CÓDIGO EM PHP PARA GERAR RELAÇÕES ENTRE COAUTORES}

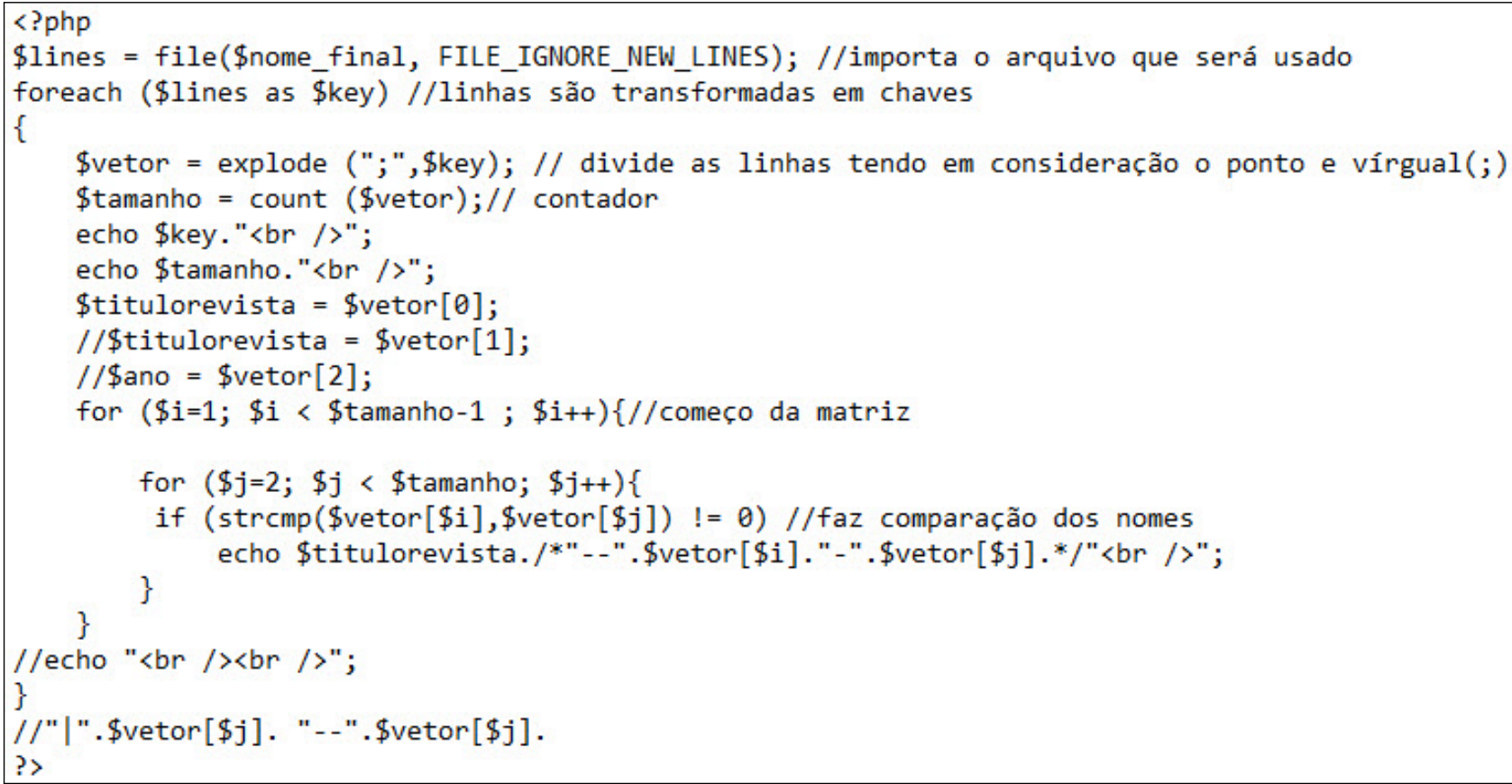

